that same woman hears of a woman who is pregnant she coaches her and uses her utmost endeavors to inveigle her to employ her husband. This same man advertises his confinement cases in the secular press after they have occurred.

Physicians even prostitute the church for the furtherance of their intereste. Not long ago two ladies joined a certain church. At the instance of a physician who was a member of that church, the pastor called upon these ladies within a week after their reception into the church and requested them to employ the above-mentioned physician, though they assured the pastor that they were well satisfied with their present medical attendant, who had borne that relation to them for the last twentyfive years.

Neither are the features thus far enumerated the only evils that have taken possession of the profession. How of ten do we commence the perusal of an article in some reputable medical journal by a physician who has a high standing in the profession, only to find that the said article, instead of being devoted to the advancement of medical science, is written to extol the virtues of some proprietary article, or in the interests of some manufacturing firm. It is needless to mention the fee that he gets for this article, or the elasticity of his conscience, though the act does detract from the standing of the entire profession. Nor is the medical press immune to this disease. As every intelligent physician is supposed to read, it is entirely unnecessary to mention the different ways in which it is perverted.

These lines are not written in a spirit of querulousness, but every physician engaged in active practice knows that they are facts that can not be gainsaid. Admitting this to be true, the caption at the head of this article naturally presents itself. If this disease which infects the profession is not already ma lignant, it will soon become so-provided it continues. Is there a remedy? Would it not be of profit to the AMERICAN MEDICAL Associátion at its next session to direct a little of the force it expends vpon scientific papers in the direction of the correction of these evils?

Theo. I. HАтch, M.D,

Incarceration of the Penis.

Lead, S. D., Dec. 29, 1898.

To the Editor:-The five-year-old son of P. G. recently awakened suddenly and began crying as if in severe pain. An examination by his mother failed to reveal any cause, but hecontinued to suffer and two or three days later, while giving a bath, the mother found the penis greatly swollen and brought the boy to the hospital, when examination revealed a badly swollen penis, about the size of an adult's in a flaccid condition, with very edematous prepuce, uniform in size, but at the base of the penis a fissure involving the entire circumference of the penis and just behind this fissure an absence of swelling. By opening this fissure I found a swall black cotton thread deeply imbedded, and which had cut nearly through the corpora epongiosum and almost into the urethra. The pressure had caused some cyanosis of the organ. It was impossible to learn how long the thread had been there, but after its removal the organ rapidly assumed its normal condition.

Herman S. Judd, M.D.

\section{Home Treatment of Chronic Morphinism.}

Cleveland, Ohio, Dec. 26, 1898.

To the Editor:-I notice an article on page 1423 of the Journal (Dec. 10, 1868) on the above title. I am somewhat at a loss to understand whether the item was published for the eake of condemning the method or not. I think that it must have that effect on the profession and am sure that it will have on the habitue. Any method of treatment that is of itself cruel enough to torture patients to the extent of driving nearly

per cent. of them to suicide within three days of the time of commencing it, should be classed with the cruelties of Nero rather than as belonging to modern medicine.

I have treated thirty cases of chronic morphinism in the past year, some of them taking as much as 40 grains per day hypodermically (I never refuse a patient because of the amount taken), and have not failed to make a cure in any single case. I have had no suicides or attempts at suicide. I have never found it necessary to employ more than one nurse for ten patients, but do find that I must have the patients at my institution. I have devoted my entire time to the treatment of this class of cases for the past six years and have never found a case that I could not cure, provided he wanted to be cured, and that without extreme suffering. Most patients do not suffer at all. Some of them have told me they felt better from the time they commenced treatment until they were cured than while themselves taking the morphin.

I will be glad to explain my methods to any physician who may be interested.

A. J. Pressey, M.D.

\section{Lepra Bacilli Found in the Brain.}

New York, Dec. 23, 1898.

To the Editor:-Hansen said the brain is never affected by leprosy. Dr. C. Brutzer (St. Petersburg Med. Woch., Oct. 17 and 19,1898 , No. 42, p. 363), reports ten autopsies of lepers who had died in the leprosery of Riga, and in four of these cases there were adhesions between the dura mater and the brain; in three of these four cases of adherent meningitis, he found lepra bacilli au niveau de la glande pituitaire. Evidently Hanson is wrong in his opinion that "the brain is never affected by leprosy." ALBERT S. Ashmead, M.D.

\section{SOCIETY NEWS.}

Chicago Pathological Society.- The second annual address before this Society was delivered by W. T. Councilman, M.D., professor of pathology in Harvard Medical School, Wednesday evening, Dec. 28, 1898, on the subject of "Inflammatory Processes Illustrated in Acute Inflammation of the Cornea."

N. Y. Academy of Medicine.-At the meeting, Dec. 15, 1898, the following officers were elected : President, William H. Thomson ; vice-president, Herman Knapp ; trustee, E. G. Janeway ; treasurer, for the trustees, W. F. Cushman; member of committee on admissions, Reginald H. Sayre, and member of library committee, A. Caille.

An International Congress. - The ninth international Congress against the Abuse of Alcohol, to be held in Pariq, April 4 to 6 , 1899, has appointed Dr. T. D. Crothers of Hartford, Conn., foreign coresponding secretary. This Congress is presided over by Dr. Legrain, an eminent specialist, and superintendent of the Asylum of the Seine for Mental Diseases. The preliminary program gives the names of several of the most prominent medical men of Europe as readers of papers on the scientific side of the drink problem.

Phlladelphia Pathological Society.-At the last meeting of this society the following program was carried out: Dr. A. Ferree Witmer spoke on "A Study in Involution" ; Dr. J. H. Johnson, on "Fistula of Appendix Following an Appendicial Abscess"; Drs. Sailer and Greisinger presented "Specimens From a Case of Typhoid Fever"; Dr. David Riesman spoke on "Hemorrhagic Infarction of the Mesentery and Intestine," also "Vari$\operatorname{cose}$ Veins of Esophagus"; and Dr. W. E. Hughes, on "Aneurysm of Thoracic Aorta."

Philadelphia Pharmaceutical Society.-At the last meeting of this society, Mr. William Thompson read a paper on "Some Observations on Abstracts in Comparison with Fluid Extracts," in whick he did not favor the use of the former until further clinical experiments had been made. Dr. Lyman Kebler spoke 